\title{
Clinical, Pathological and Immunohistochemical Evaluation of a Primary Hemangiosarcoma in a Pinscher Dog
}

\author{
Denner Santos dos Anjos ${ }^{1}$, Andreia Regis Assis ${ }^{2}$, Carlos Eduardo Fonseca-Alves ${ }^{3}$ \& Veronica Jorge Babo-Terra ${ }^{4}$
}

\begin{abstract}
Background: Hemangiosarcoma (HSA) is a malignant tumor that arises from the vascular endothelium affecting more often dogs than other species as cats, cows and horses. It comprises approximately $2 \%$ of all tumors in dogs. The most common primary site for the HSA in dogs is the spleen, and other locations include the right atrium, pericardium, liver and prostate. Other authors have reported this tumor in lungs, kidney, oral cavity, muscle, bone, urinary bladder, left ventricle, tongue and retroperitoneum. Due to the importance of the HSA in canine species, the aim of this study was to describe the clinical and pathological findings, besides therapeutic protocol in an unusual case of HSA.

Case: A six-year-old male pinscher was referred to the veterinary hospital with a history of cyanosis and choking. The animal was submitted to radiographic examination in lateral cervical view, which identified the presence of a mass of $1.2 \mathrm{~cm}$ in diameter near the pharynx. In order to evaluate the oral cavity, general anesthesia was performed, and it was possible to see a soft, rosy, circumscribed and vascularized lump in pharyngeal region. Due to suspicion of neoplasm, excisional biopsy without surgical margin was performed. The histopathological exam diagnosed hemangiosarcoma. Immunohistochemistry against vimentin, factor VIII, VEGF and Ki67 was performed and confirmed diagnosis of low grade hemangiosarcoma. Antineoplastic chemotherapy protocol was initiated with doxorubicin and cyclophosphamide every 21 days totaling six sessions. However, the animal died after the cyclophosphamide intoxication with a three-fold recommended dose (660 $\mathrm{mg} / \mathrm{m}^{2}$ total in the last session), showing a median survival rate of 220 days.

Discussion: The most common primary site for HSA in dogs is the spleen. The pharyngeal location is rare, with only a few reports in literature. In the present case, solitary tumor was observed in pharynx with no involvement of other organs, evidenced by radiographic examination, abdominal ultrasound and echocardiogram, suggesting that pharynx was the primary location of the tumor. Main features of HSA comprise a solitary nodule or multifocal lesions within the organ or widely disseminated. Histologically, they consist of pleomorphic immature endothelial cells with formation of vascular spaces with variable amount of blood and/or thrombi. In some cases, HSA shows a polymorphic subtype and immunohistochemistry is necessary to provide a definitive diagnosis. The sample was submitted to histopathological examination which revealed proliferation of endothelial cells with pronounced pleomorphism ranging from polygonals to ovoid, sparse cytoplasm, round to oval nucleus with visible nucleolus, few mitotic figures, some of them, aberrant, which confirmed diagnosis of HAS. Due to the unusual location, we performed immunohistochemical staining for vimentin, factor VIII, VEGF and Ki67 antibodies to confirm mesenchymal origin of the tumor. In IHC, it was possible to identify positive reaction for vimentin protein, factor VIII, VEGF and few Ki67 positive cells, confirming histopathological diagnosis. Despite literature describes an aggressive biological behavior of canine HSA, with common occurrence of metastasis, recurrence was not observed at the site of the removal of the tumor. In histopathological evaluation, it was observed low number of mitoses, besides the low Ki67 expression on IHC, featuring a low grade tumor with minor ability to metastasize. To the author's knowledge, this case describes an unusual presentation of HSA, with low metastatic potential, in which chemotherapy protocol achieved survival time of 220 days.
\end{abstract}

Keywords: angiosarcoma, dogs, immunohistochemistry, pharynx.

${ }^{1}$ Master's Student, Post-Graduation Program in Animal Science, Franca University (UNIFRAN), Franca, SP, Brazil. ${ }^{2}$ DVM Autonomous, diagnostic imaging service-VetDx Service, Campo Grande, MS, Brazil. ${ }^{3}$ Department of Veterinary Clinic, School of Veterinary Medicine and Animal Science, University Estadual Paulista (UNESP), Botucatu, SP. ${ }^{4}$ Department of Small Animal Practice at Federal University of Mato Grosso do Sul (UFMS), Campo Grande, MS. CORRESPONDENCE: D.S. Anjos [dennerbiovet@ hotmail.com - Tel.: +55 (67) 8144-8191]. Franca University UNIFRAN. Av. Dr. Armando de Sáles Oliveira n. 201. Parque Universitário. CEP 14404-600 Franca, SP, Brazil. 


\section{INTRODUCTION}

Hemangiosarcoma (HSA) is a malignant tumor that arises from the vascular endothelium affecting more often dogs than other species as cats, cows and horses [19,23]. It comprises approximately $2 \%$ of all tumors in dogs [8] and $45 \%$ to $51 \%$ of splenic tumors $[3,21]$. Affects most frequently middle-aged to older animals, although there are reports of dogs with less than 3 years of age affected by the disease [5].

The most common primary site for the HSA in dogs is the spleen, and other locations include the right atrium, pericardium, liver and prostate [5]. Other authors report this tumor in lungs, kidney, oral cavity, muscle, bone, urinary bladder, left ventricle, tongue and retroperitoneum [1,4,10-12].

Main features of HSA comprise a solitary nodule, or multifocal lesions within the organ or widely disseminated. The nodules show varying sizes, are light gray to red or dark purple; soft or flabby, often filled by blood or necrotic areas on the surface. They are little circumscribed and not encapsulated, often adhered to adjacent organs and friable [24].

Histologically, they consist of pleomorphic immature endothelial cells with formation of vascular spaces with variable amount of blood and/or thrombi [7]. In some cases, HSA shows a polymorphic subtype and immunohistochemistry is necessary to provide a definitive diagnosis. Von Willebrand's factor (factor VIII related antigen), CD31 or platelet endothelial cell adhesion molecule (PECAM-1) can be used to demonstrate endothelial origin and confirm HSA diagnosis [7,15,25].

Due to the importance of the HSA in canine species, the aim of this study was to describe the clinical and pathological findings, besides therapeutic protocol in an unusual case of HSA.

\section{CASE}

A six-year-old male Pinscher was referred to the Veterinary Hospital at Federal University of Mato Grosso do Sul (UFMS), with a history of choking and cyanosis. On physical examination, it was noted difficult breathing and dry cough with no changes in physiological parameters. Due to respiratory distress, the animal was forwarded to radiographic examination in lateral cervical view, which identified the presence of a mass of $1.2 \mathrm{~cm}$ in diameter near the pharynx (Figure 1). In order to evaluate the oral cavity of the animal, inducing anesthesia was performed with $1 \%$ propofol solution (Diprivan $\left.{ }^{\circledR}\right)^{1}$ and for maintenance isoflurine was used (Isoflurane $\left.{ }^{\circledR}\right)^{2}$. The procedure allowed the visualization of a soft, pink, circumscribed and vascularized lump in pharyngeal region (Figure 2). Due to suspicion that the mass as a neoplasm, excisional biopsy was performed, without possibility of surgical margin due to the location.

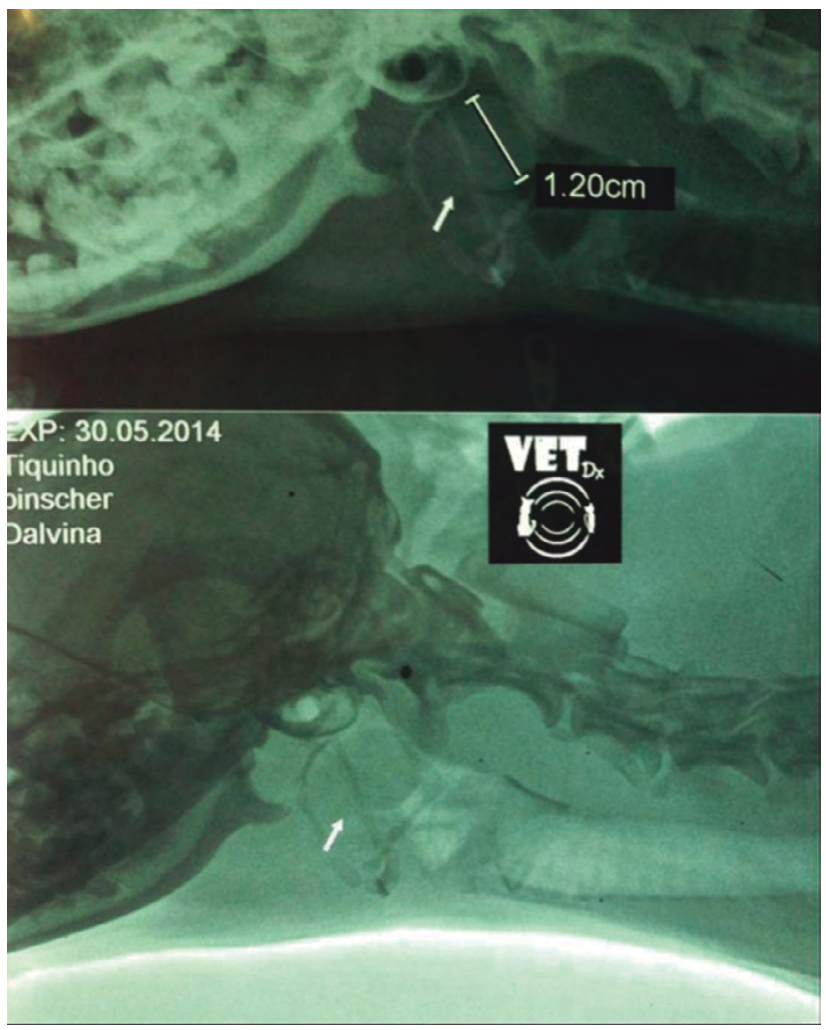

Figure 1. Lateral cervical view of a Pinscher observing the presence of a mass of $1.2 \mathrm{~cm}$ in diameter near the pharynx.

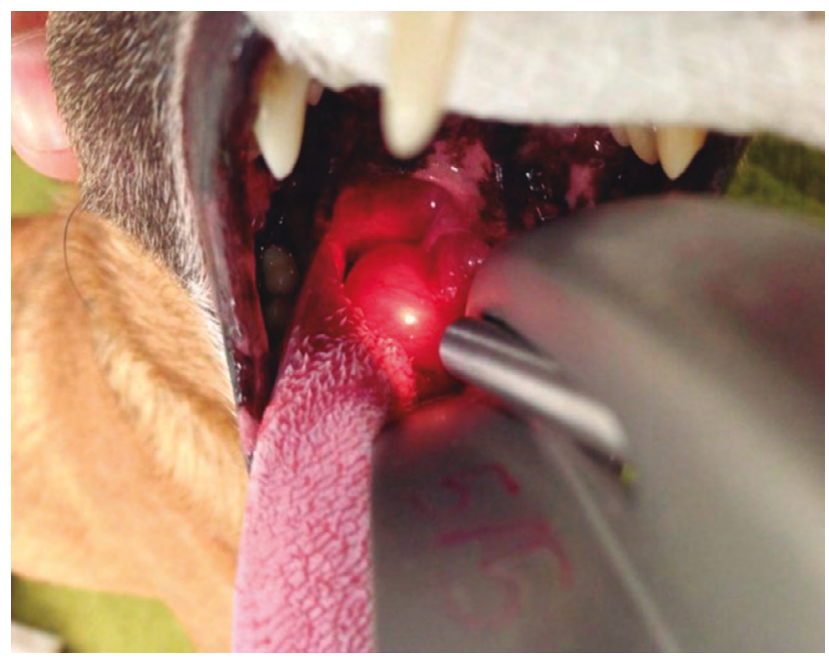

Figure 2. Canine. 6-year-old. Oral exam showing a soft, rosy, circumscribed and vascularized lump in pharyngeal region. 
The sample was submitted to histopathological examination which revealed proliferation of endothelial cells with pronounced pleomorphism ranging from polygonals to ovoid, sparse cytoplasm, round to oval nucleus with visible nucleolus, few mitotic figures, some of them, aberrant, which confirmed diagnosis of HSA. After surgical excision, remission of respiratory signs was observed. Due to the unusual location, we performed immunohistochemical staining for vimentin, factor VIII, VEGF and Ki67 antibodies to confirm mesenchymal origin of the tumor. The immunohistochemical staining was performed using peroxidase method and 3,3' diaminobenzidine tetrachloride (DAB). The slides were dewaxed in xylol and rehydrated in graded ethanol. For antigen retrieval the slides were incubated in citrate buffer $(\mathrm{pH}$ 6.0 ) in a pressure cooker (Pascal ${ }^{\circledR}$; Dako, Carpinteria, CA, USA).

Anti-factor VIII was detected with a monoclonal antibody (Abcam, ab20837) at a 1 in 500 dilution, applied for $45 \mathrm{~min}$. The antibody against Vimentin was a monoclonal mouse antibody (V9, Invitrogen), used at a 1:300 dilution for $45 \mathrm{~min}$. Ki67 antibody was monoclonal mouse antibody (Dako Cytomation) which was used at a 1 in 50 dilution for 45 min and a VEGF monoclonal antibody (Dako Cytomation) at a 1 in 50 dilution for $45 \mathrm{~min}$.

After this, slides were placed on Dako Cytomation autostainer platform. The immunolabelling was performed by the Histofine method (414154F, Nichirei Biosciences, Tokyo, JP). The sections were then counterstained with haematoxylin, dehydrated, mounted in Etellan, and examined with a light microscope at $400 \mathrm{X}$ magnification. In all immunolabelled batches, omission of the primary antibody and replacement with the diluting solution alone served as a negative control. Positive control consisted of normal canine ovary gland for estrogen and progesterone receptor, carcinoma known positive for cytokeratin, mesenchymal tumor known positive for vimentin. A negative control was performed for all antibodies by omitting the primary antibody and substituting with Tris-buffered saline. In IHC it was possible to identify positive reaction for vimentin protein, factor VIII, VEGF and few Ki67 positive cells, confirming histopathological diagnosis (Figures $3 \& 4$ ).
Due to the unfavorable prognosis of HSA it was recommended neoadjuvant chemotherapy, but the owner did not agree consent. Three months after surgery, clinical evaluation and x-rays of the dog were performed and no changes that could indicate tumor recurrence have been found. At that moment, the owner decided to accept neoadjuvant chemotherapy. Protocol was established with doxorubicin hydrochloride (Doxorubicin hydrochloride $10 \mathrm{mg})^{3}$ at a dose of $1 \mathrm{mg} / \mathrm{kg}$ every three weeks and cyclophosphamide (remanipulated at DrogaVet veterinary pharmacy; Genuxal $\left.{ }^{\circledR} 50 \mathrm{mg}\right)^{4}$ at a dose of $50 \mathrm{mg} / \mathrm{m}^{2}$ orally on days D2, D3, D4, D5 (full dose $200 \mathrm{mg} / \mathrm{m}^{2}$ ), starting two days after doxorubicin, totaling six sessions. During treatment, blood examinations have showed some alterations such as leukopenia, thrombocytopenia and increased serum concentration of alanine aminotransferase (ALT).

However, during the last session of chemotherapy the owner mistakenly administered $220 \mathrm{mg} / \mathrm{m}^{2}$ of cyclophosphamide per day for three days (total of $660 \mathrm{mg} / \mathrm{m}^{2}$ ). After this episode, the animal presented vomiting, anorexia, pollakiuria, stranguria and hematuria. The dog was forwarded to abdominal ultrasound, which revealed hyperechoic liver and kidneys and an irregular and thick bladder wall. Urine was submitted for urinalysis, which demonstrated proteinuria, hematuria and epithelial cells, suggesting sterile hemorrhagic cystitis by cyclophosphamide. The red blood count showed intense leukopenia and thrombocytopenia (100 leukocytes [reference interval 6,000 - 17,000 x $10 \mathrm{~m}^{3}$ ] and seven thousand platelets [reference interval 200,000 - 500,000], respectively).

The animal was put on intensive care with fluidtherapy $\mathrm{NaCl} 0.9 \%$ (cloreto de sódio $\left.{ }^{\circledR} 0,9 \%\right)^{4}$, Propionyobacterium acnes as an immunomodulator at a dose of $\left.1 \mathrm{~mL} \mathrm{IM} \mathrm{(Infervac}{ }^{\circledR}\right)^{5}, 8 \mathrm{mg} / \mathrm{kg}$ of a single dose intravenous of sodium cefovecina $\left(\text { Convenia }{ }^{\circledR}\right)^{6}$, maropitant $1 \mathrm{mg} / \mathrm{kg}$, once a day, $\left(\text { Cerenia }^{\circledR}\right)^{6}$, meloxicam $0.15 \mathrm{mg} / \mathrm{kg}$ once a day $\left(\text { Maxicam }^{\circledR} 0.5 \mathrm{mg}\right)^{7}$ and Silymarin $10 \mathrm{mg} / \mathrm{kg}$ every $12 \mathrm{~h}\left(\text { Legalon }^{\circledR}\right)^{8}$. However, two days after hospitalization, the animal presented intense crisis of dyspnea and died. The owner did not authorize the necropsy. 


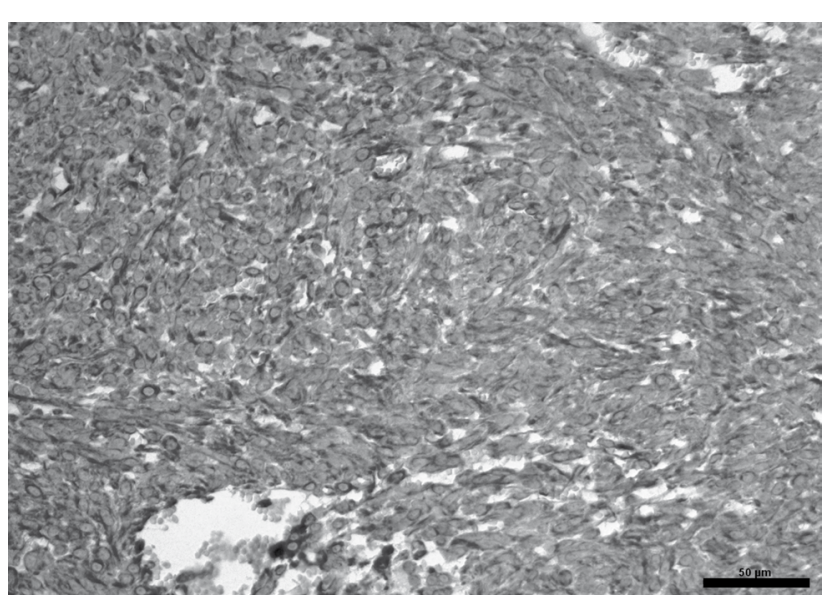

Figure 3. Photomicrographs of canine hemangiosarcoma, immunohistochemistry, anti-factor VIII antibody. It is possible to note the diffuse positive immunoreaction by mesenchymal cells, as well as the endothelial cells (internal positive control). DAB, 20x [50 $\mu \mathrm{m}]$.

\section{DISCUSSION}

The most common primary site for HSA in dogs is the spleen [5]. The pharyngeal location is rare, with only a few reports in literature $[6,9,17]$. In the present case, solitary tumor was observed in pharynx with no involvement of other organs, evidenced by radiographic examination, abdominal ultrasound and echocardiogram, suggesting that pharynx was the primary location of the tumor, which is not in accordance with previous reports that describe the location of pharynx as metastatic focus of the neoplasm.

Despite literature describes an aggressive biological behavior of canine HSA, with common occurrence of metastasis [26], recurrence was not observed at the site of the removal of the tumor, nor the presence of metastatic structures in other organs during the period of treatment. This fact can be associated to a unique biological behavior of this tumor in this location. In histopathological evaluation, it was observed low number of mitoses, besides the low Ki67 expression on IHC, featuring a low grade tumor with minor ability to metastasize.

Chemotherapy protocols using doxorubicin or vincristine, and cyclophosphamide have been reported to lead to the best survival time for canine HAS [2]. In this case, it was observed good acceptance to antineoplastic treatment, with minimal side effects. However, the dog died after 220 days of starting treatment because of cyclophosphamide intoxication. The combination of surgery and chemotherapy can increase the survival time (median of 140-180 days), so that 33\% of the treated animals can overcome a year of survival [14]. Another

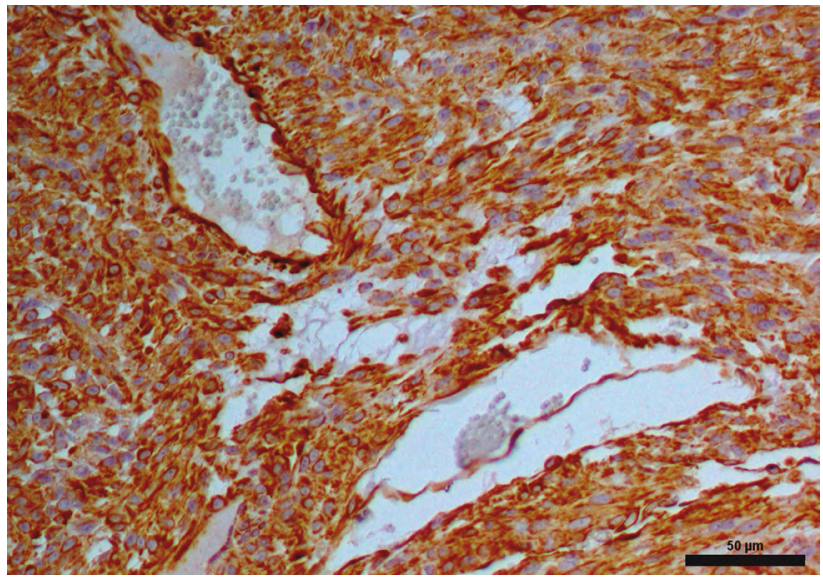

Figure 4. Photomicrographs of canine hemangiosarcoma, immunohistochemistry, anti-VEGF antibody. Positive cytoplasmic immunoreaction by neoplastic cells. DAB, 20x [50 $\mu \mathrm{m}]$.

article reported an average survival time for splenic HSA of 202 days treated with doxorubicin and cyclophosphamide [20]. One study used the histological degree scheme and it has been shown that dogs with low-grade neoplasms have better prognosis compared to highintermediate-grade neoplasms [16]. This corroborates the findings found in IHC of this animal, in which it was observed low Ki67 expression and low number of mitoses, suggesting less ability to metastasize.

In this case, the animal was expected to have a survival rate higher than 220 days, but it was decreased due to the intoxication of cyclophosphamide. Cyclophosphamide is a nitrogen mustard that may be given orally in dogs, showing low toxicity, which include bone marrow suppression and sterile haemorrhagic cystitis [18,22]. One study observed the development of hemorrhagic cystitis in three dogs in the indicated therapeutic dose $\left(100-250 \mathrm{mg} / \mathrm{m}^{2}\right)$ [18]. Although hemorrhagic cystitis is unusual in conventional doses, high doses can lead to this complication as the case described, which took $150 \mathrm{mg}$ total of cyclophosphamide $(660 \mathrm{mg} / \mathrm{m} 2)$, corresponding to three times the total recommended dose. The dog showed severe signs of intoxication, with myelosuppression and hemorrhagic cystitis, and died even after conservative treatment. In human patients, it was observed pathological evidence of hemorrhagic cystitis after a single dose of $660 \mathrm{mg} /$ $\mathrm{m}^{2}$ of cyclophosphamide [13].

To the author's knowledge, the case describes an unusual presentation of HSA, with low metastatic potential, in which chemotherapy protocol achieved survival time of 220 days. 


\section{MANUFACTURERS}

${ }^{1}$ Laboratório Abbott-Eurofarma. São Paulo, SP, Brazil.

${ }^{2}$ Instituto BioChimico Ind. Farm. Ltda. Itatiaia, RJ, Brazil.

${ }^{3}$ Laboratório Glenmark Pharmaceutical Ltda. São Paulo, SP, Brazil.

${ }^{4}$ Baxter Hospitalar Ltda. São Paulo, SP, Brazil.

${ }^{5}$ Hertape Saúde Animal S.A. (Calier Laboratories S.A.). Juatuba, MG, Brazil.
${ }^{6}$ Pfizer Ltda. São Paulo, SP, Brazil.

${ }^{7}$ Ourofino Animal Health Ltda. Cravinhos, SP, Brazil.

${ }^{8}$ Nycomed Pharma Laboratório. São Paulo, Brazil.

Declaration of interest. The authors report no conflicts of interest. The authors alone are responsible for the content and writing of the paper.

\section{REFERENCES}

1 Brown N.O., Patnaik A.K. \& MacEwen E.G. 1985. Canine hemangiosarcoma:retrospective analysis of 104 cases. Journal of American Veterinary Medical Association. 186: 56-58.

2 Clifford C.A., Mackin A.J. \& Henry C.J. 2000. Treatment of canine hemangiosarcoma: 2000 and beyond. Journal of Veterinary Internal Medicine. 14: 479-485.

3 Day M.J., Lucke V.M. \& Pearson H. 1995. A review of pathological diagnoses made from 87 canine splenic biopsies, Journal of Small Animal Practice. 36(10): 426-433.

4 Dennis M.M., Ehrhart N., Duncan C.G., Barnes A.B. \& Ehrhart E.J. 2006. Frequency of and risk factors associated with lingual lesions in dogs: 1,196 cases (1995-2004). Journal of American Veterinary Medical Association. 228: 1533-1537.

5 Fernandes S.C. \& Nardi A.B. 2009. Hemangiossarcoma. In: Suely Rodaski (Ed). Oncologia em cães e gatos. Rio de Janeiro: Editora Roca Ltda., pp.526-537.

6 Flores M.M., Panziera W., Kommers G.D., Irigoyen L.F., Barros C.S.L. \& Fighera R.A. 2012. Aspectos epidemiológicos e anatomopatológicos do hemangiossarcoma em cães: 40 casos (1965-2012). Pesquisa Veterinária Brasileira. 32(12): 1319-1328.

7 Gamlem H. \& Nordstoga K. 2008. Canine vascular neoplasia- histologic classification and inmunohistochemical analysis of 221 tumours and tumour-like lesions. Acta Pathologica Microbiologica Scandinavica. Suppl.(125): 19-40.

8 Guinan J., Fischetti A., Garate A.P. \& Chalhoub S. 2012. Primary periaortic hemangiosarcoma in a dog. Cancer Veterinary Journal. 53(11): 1214-1218.

9 Head K.W., Else R.W. \& Dubielzing R.R. 2002. Tumors and tumor like lesions of vascular tissue. In: Donald Meuten (Ed). Tumors in Domestic Animals. 4th edn. Ames: Iowa State Press, pp.434-435.

10 Liptak J.M., Dernell W.S. \& Withrow S.J. 2004. Haemangiosarcoma of the urinary bladder in a dog. Australian Veterinary Journal. 82(4): 215-217.

11 Liptak J.M., Dernell W.S., Ehrhart E.J., Rizzo S.A., Rooney M.B. \& Withrow S.J. 2004. Retroperitoneal sarcomas in dogs: 14 cases (1992-2002). Journal of American Veterinary Medical Association. 224: 1471-1477.

12 Locke J.E. \& Barber L.G. 2006. Comparative aspects and clinical outcomes of canine renal hemangiosarcoma. Journal of Veterinary Internal Medicine. 20: 962-967.

13 Marshall A., McGrath C., Torigian D., Papanicolaou N., Lal P. \& Kaplan Tweed C. 2012. Low-dose cyclophosphamide associated with hemorrhagic cystitis in a breast cancer patient. Breast Journal. 18: 272-275.

14 Merlo E.M. \& Muñoz L.A. 2011. Hemangiosarcoma canino. In: Elena Martinez Merlo (Ed). Manual práctico de oncología en pequeños animales. Madrid: Salud Animal, pp.161-180.

15 Miller M.A., Ramos J.A. \& Kreeger J.M. 1992. Cutaneous vascular neoplasia in 15 cats: clinical, morphologic, and immunohistochemical studies. Veterinary Pathology. 29: 329-336.

16 Ogilvie G.K., Powers B.E., Mallinckrodt C.H. \& Withrow S.J. 1996. Surgery and doxorubicin in dogs with hemangiosarcoma. Journal of Veterinary Internal Medicine. 10: 379-384.

17 Papadimitriou A.S., Anatolitou A., Brellou G., Kouki M.I. \& Viemmas I. 2014. Gingival hemangiosarcoma of the left mandible in a dog. The Journal of Veterinary Medical Science. 2(1): 4.

18 Peterson J., Couto C., Hammer A. \& Ayl A.D. 1992. Acute sterile hemorrhagic cystitis after single intravenous administration of cyclophosphamide in three dogs. Journal of American Veterinary Medical Association. 201: 1572-1573.

19 Schultheiss P.C. 2004. A retrospective study of visceral and nonvisceral hemangiosarcoma and hemangiomas in domestic animals. Journal of Veterinary Diagnostic Investigation. 16: 522-526.

20 Sorenmo K.U., Jeglum K.A. \& Helfand S.C. 1993. Chemotherapy of canine hemangiosarcoma with doxorubicin and cyclophosphamide. Journal of Veterinary Internal Medicine. 7: 370-376. 
21 Spangler W.L. \& Kass P.H. 1997. Pathologic factors affecting postsplenectomy survival in dogs. Journal of Veterinary Internal Medicine. 11: 166-171.

22 Stanton M. \& Legendre A. 1986. Effects of cyclophosphamide in dogs and cats. Journal of American Veterinary Medical Association. 188: 1319-1322.

23 Stock M.L., Smith B.I. \& Engiles J.B. 2011. Disseminated hemangiosarcoma in a cow. Cancer Veterinary Journal. 52: 409-413.

24 Thamm D.H. 2013. Miscellaneous tumors. In: Withrow \& MacEwen's (Ed). Small Animal clinical oncology. 5th edn. St. Louis: Elsevier, pp.679-687.

25 Von Beust B.R., Suter M.M. \& Summers B.A. 1988. Factor VIII-related antigen in canine endothelial neoplasms: An immunohistochemical study. Veterinary Pathology. 25: 251-255.

26 Ward H., Fox L.E., Calderwood-Mays M.B., Hammer A.S. \& Couto C.G. 1994. Cutaneous hemangiosarcoma in 25 dogs: a retrospective study. Journal of Veterinary Internal Medicine. 8: 345-348. 